\title{
Short-Lived Isotopic Chronometers- A Means of Measuring Decadal Sedimentary Dynamics
}

Over the past three decades, there has been a dramatic increase in the volume and scope of research defining the sources and fate of anthropogenic substances and the environmental changes that they may cause. An important aspect of the research is the determination of the rate at which these changes are occurring.

The best method of assessing rates of change in ecosystems is by long-term monitoring. However, such information is unavailable for most ecosystems, and other means must be employed. In sedimentary environments, chronological scales can be determined by the distribution of radioactive isotopes in the sediment. These timescales are developed by using a known property of radioactive material, the "half-life." The half-life of an isotope is the amount of time it takes for half a given number of radioactive atoms to decay to another element. The age of the sediment containing a radioactive isotope with a known half-life can be calculated by knowing the original concentration of the isotope and measuring the percentage of the remaining radioactive material.

The requirements for a radioisotope to be a candidate for "dating" are that: (1) the chemistry of the isotope (element) is known; (2) the half-life is known; (3) the initial amount of the isotope per unit substrate is known or accurately estimated; (4) the only change in concentration of the isotope is due to radioactive decay; and (5) in order to be useful, it must be relatively easy to measure. If all these conditions are met, the effective range for each isotope is about eight half-lives. Four radioisotopes $\left({ }^{7} \mathrm{Be},{ }^{14} \mathrm{C},{ }^{137} \mathrm{Cs}\right.$, and $\left.{ }^{210} \mathrm{~Pb}\right)$ satisfy these criteria, and are useful for measuring sedimentary dynamics over the last 100 to 150 years. The following summarizes the uses and potential uses of these four radioisotopes in dating recent sediment.

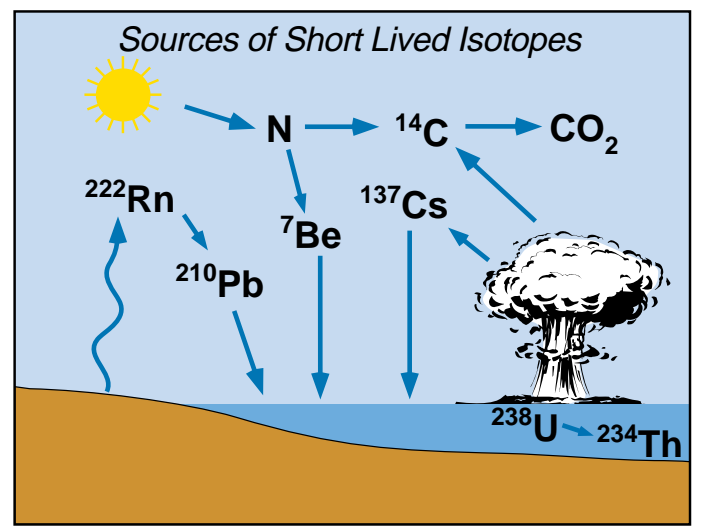

Beryllium-7 ${ }^{7} \mathrm{Be}$ is a naturally produced radioisotope that is formed by cosmic ray bombardment of atmospheric nitrogen $(\mathrm{N})$ and oxygen $(\mathrm{O})$. It is transferred through precipitation from the atmosphere to earth. Beryllium is a highly reactive element and becomes rapidly and tightly associated with a sedimentary substrate. ${ }^{7} \mathrm{Be}$ has a half-life of 53 days, which makes its effective range of applicability for dating sediment about 1 year. Thus, detection of its presence is a reliable indicator that the substance

\section{How Radiodating Works}

Radiodating is based on the radioactive decay of specific isotopes in sediments. The radiometric "clock" can be conceptualized as an hourglass, in which the sand in the upper and lower reservoirs represents the parent and daughter isotopes, respectively. By measuring the ratio of the sand in the two reservoirs, the length of time the hourglass has been running can be determined, provided the following conditions are satisfied:

(1) the rate of sand falling from the upper to lower reservoir is known (corresponding to the half-life of the parent isotope)

(2) when the hourglass is started (time $T_{0}$ ), either the lower reservoir is empty or the initial amount is known

(3) sand may only be added to the lower reservoir from the upper reservoir, and no sand may be lost from the lower reservoir
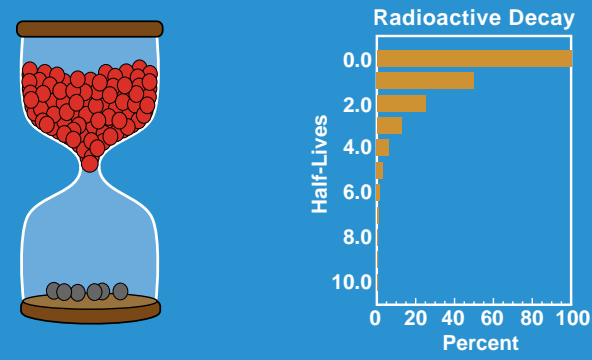

In sediments, the clock begins counting at the time when the sediment particle is deposited and exchange between the water and particle stops. As the particles are subsequently buried, the parent isotope decays to its daughter.

Adapted from Geyh and Schleicher, 1990

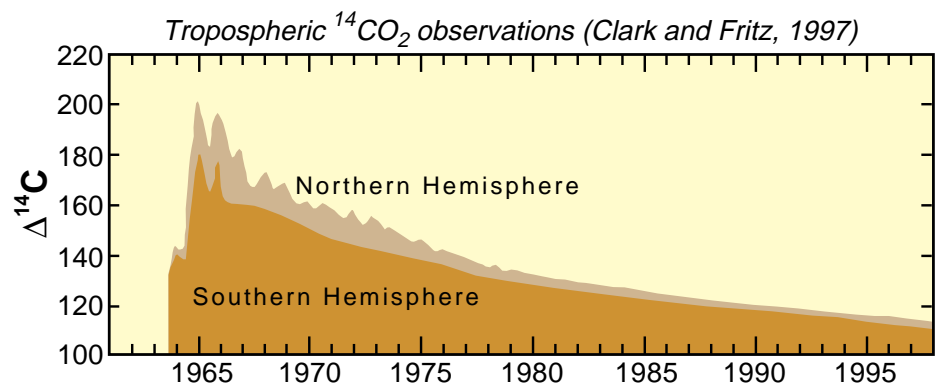

was in contact with the atmosphere within the past year. This information is important, as it is used to calibrate other isotope-based geochronometers and define sedimentary sinks.

Carbon-14 ${ }^{14} \mathrm{C}$ is produced in the Earth's atmosphere by the interaction of cosmic ray particles with nitrogen $(\mathrm{N})$, oxygen $(\mathrm{O})$, and carbon $(\mathrm{C})$. Of these elements, nitrogen is the most important in terms of the amount of ${ }^{14} \mathrm{C}$ produced. ${ }^{14} \mathrm{C}$ was also produced by thermonuclear activity (bomb testing), which contributed significantly to the atmosphere, reaching its peaks in 1963 (Northern Hemisphere) and 1964 (Southern Hemisphere). All ${ }^{14} \mathrm{C}$ produced is rapidly oxidized to $\mathrm{CO}_{2}$ and is assimilated into the carbon cycle. As $\mathrm{CO}_{2}$ becomes incorporated in all carbon-based materials, balance is established between intake, respiration, and decay. ${ }^{14} \mathrm{C}$ has a halflife of 5,730 years and has an effective range of applicability of 100 to 70,000 years for dating organic material. The amount of bombproduced carbon is determined by comparing present radiocarbon 
activity to 1950 carbon activity, the date established by convention as the baseline for all radiocarbon dating. Post-1952 carbon values are reported as a percentage of modern (that is, 1950) carbon, and denoted as $\Delta{ }^{14} \mathrm{C}$.

Cesium-137 ${ }^{137} \mathrm{Cs}$, with a half-life of 30.3 years, is a thermonuclear byproduct. Its presence in natural systems is directly related to atmospheric thermonuclear activity. The curve below shows that ${ }^{137} \mathrm{Cs}$ fallout production (and deposition) began about 1952; deposition peaked during 1963 and 1964. Under ideal conditions, the sediment profile should mimic the ${ }^{137} \mathrm{Cs}$ production. However, the inability to accurately sample small intervals, and the mixing of the sediment by organisms, often cause deviations from the ideal profile.

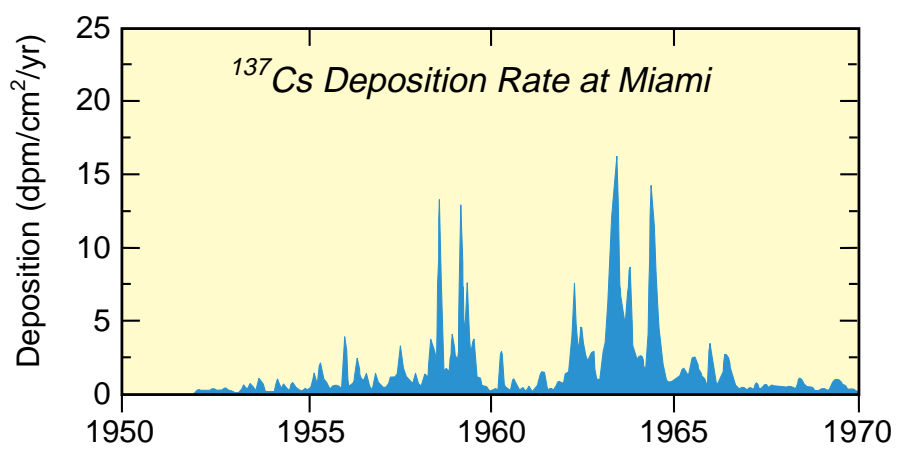

Lead-210 ${ }^{210} \mathrm{~Pb}$, with a half-life of 22.3 years, is ideal for most ecosystem studies. A member of the ${ }^{238} \mathrm{U}$ series, ${ }^{210} \mathrm{~Pb}$ forms by the decay of its intermediate gaseous parent, radon-222. ${ }^{222} \mathrm{Rn}$, formed by the decay of radium, escapes into the atmosphere by recoil or by diffusion, and rapidly decays to form ${ }^{210} \mathrm{~Pb}$. This isotope has a residence time in the atmosphere of about 10 days before it is removed by precipitation. The highly reactive lead is then rapidly adsorbed to and incorporated into the depositing sediment. This flux produces a concentration of "unsupported" ${ }^{210} \mathrm{~Pb}$ (lead whose activity in the sediment is higher than that of its radium grandparent, ${ }^{226} \mathrm{Ra}$ ). Dates of sediment deposition are calculated by determining the decrease in ${ }^{210} \mathrm{~Pb}$ activity at each selected sediment interval; this decrease is a function of time. If the initial concentration of ${ }^{210} \mathrm{~Pb}$ is known, or is estimated using ${ }^{7} \mathrm{Be}$ data, then the "age" of a sediment interval is calculated by the following:

substituting the constants,

$$
\mathrm{T}_{\mathrm{age}}=\ln \left(\mathrm{A}_{210 \mathrm{~Pb}_{0}} / \mathrm{A}_{210 \mathrm{~Pb}_{\mathrm{h}}}\right) * 1 / \lambda
$$

$$
\mathrm{T}_{\mathrm{age}}=\ln \left(\mathrm{A}_{210 \mathrm{~Pb}_{0}} / \mathrm{A}_{210} \mathrm{~Pb}_{\mathrm{h}}\right) * 1 / 0.03114 ;
$$

where $\mathrm{A}_{210} \mathrm{~Pb}_{0}$ is the unsupported ${ }^{210} \mathrm{~Pb}$ activity in disintegrations per minute at time zero (the present), $\mathrm{A}_{210} \mathrm{~Pb}_{0}$ is the activity in disintegrations per minute at depth $\mathrm{h}$, and $\lambda$ is the decay constant for ${ }^{210} \mathrm{~Pb}$. Ideally, a plot of ${ }^{210} \mathrm{~Pb}$ activity and depth will be an exponentially decreasing curve asymptotically approaching the supported value.

\section{Applications}

Lead-210 Example Core 19C (below) taken from a mudbank in Florida Bay, demonstrates the distribution of ${ }^{210} \mathrm{~Pb}$ and ${ }^{226} \mathrm{Ra}$. Dates, calculated by using the ${ }^{210} \mathrm{~Pb}$ method, were corroborated by comparing the distribution of total lead measured in the core to the total lead in a nearby coral in which the ages had been determined by annual banding. Dates determined by the ${ }^{210} \mathrm{~Pb}$ method in cores from throughout Florida Bay are now being used to construct the paleoecological history of the region.

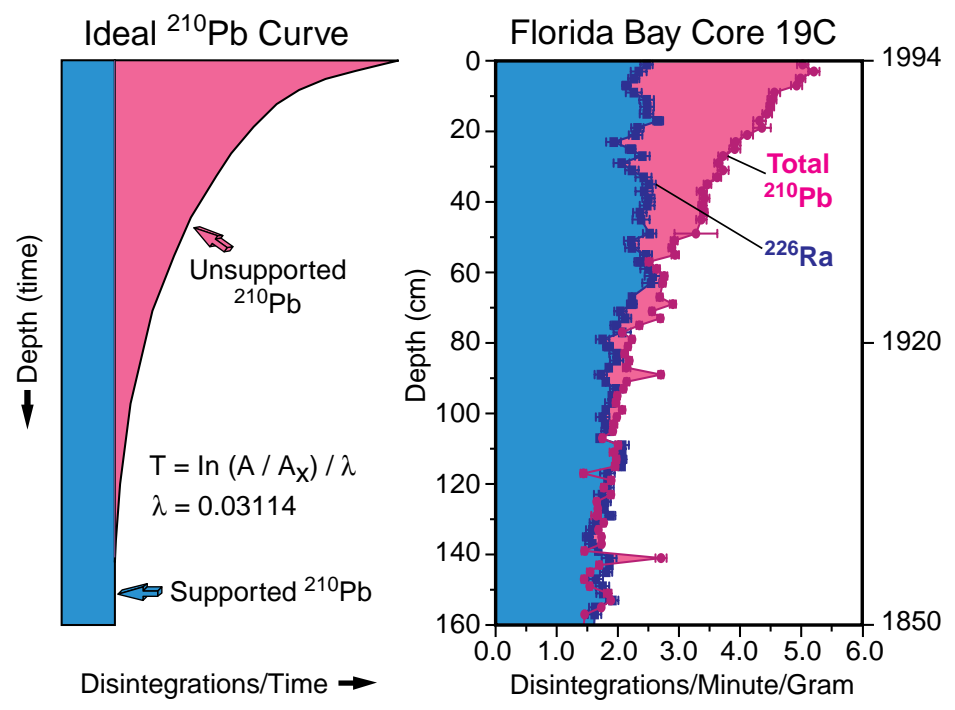

Beryllium-7 Example The presence of ${ }^{7} \mathrm{Be}$ in the uppermost section of a core is a good indicator that the most recently deposited sediment surface was recovered. ${ }^{7} \mathrm{Be}$ may also be used to determine

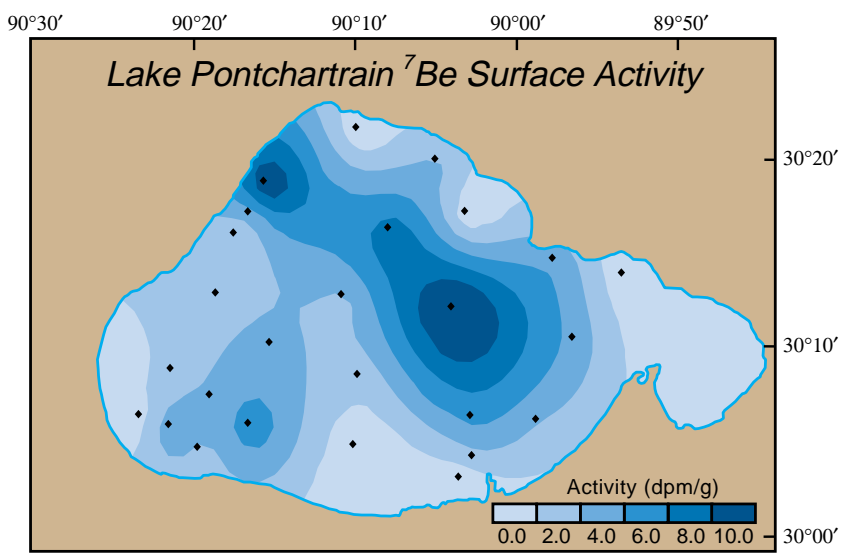

regional short-term sedimentation patterns. Because ${ }^{7} \mathrm{Be}$ attaches strongly to particles, the highest measured activity corresponds to the greatest sediment accumulation rate. The distribution of ${ }^{7} \mathrm{Be}$ in the top $1 \mathrm{~cm}$ of Lake Pontchartrain sediment (above) defines the sediment depocenters. A dynamic model for the lake suggests that these depocenters are the result of the water current pattern responding to dominant wind directions.

\section{References}

Geyh, M.A., Schleicher, H., 1990, Absolute age determination: Physical and chemical dating methods and their application: Berlin, Springer-Verlag, $503 p$.

Clark, I.D., Fritz, P., 1997, Environmental isotopes in hydrogeology: Boca Raton, Fla., Lewis Publishers, 328 p.

For more information, please contact:

Charles W. Holmes

U.S. Geological Survey

600 4th St. South

St. Petersburg, FL 33701
(813) 893-3100 ext. 3056

(813) 893-3333 (fax)

cholmes@usgs.gov

Author: Charles W. Holmes 